\title{
Exploring the Development of Team Identification
}

\author{
Daniel Lock \\ Griffith University \\ Tracy Taylor \\ University of Technology, Sydney \\ Daniel Funk \\ Temple University \\ Simon Darcy \\ University of Technology, Sydney
}

Individuals strive to attach themselves to social groups that reflect positively on the way they view themselves (Tajfel, 1972, 1982; Tajfel \& Turner, 1979). While social categories span a myriad of activities, pursuits and organizations, sport teams provide a pertinent example of social categories from which individuals derive social identity benefits (Cialdini \& Richardson, 1980). As a result, social identity theory has been extensively applied to sport consumers as a framework contributing to understanding of identity formation (Fisher \& Wakefield, 1998; James, 2001), strength (Wann \& Branscombe, 1993, 1995), structure (Heere \& James, 2007) and management for sport fans (Cialdini et al., 1976; Cialdini \& Richardson, 1980; Snyder, Lassegard, \& Ford, 1986).

Despite the broad contributions made by sport-based studies utilizing the theoretical propositions of social identity theory (Tajfel, 1972, 1982; Tajfel \& Turner, 1979), previous work has not explored how identification develops. Research in mainstream social psychology literature acknowledges that identification does develop (Crisp \& Hewstone, 2007); a position also recognized in sport management literature exploring involvement (Funk \& James, 2001, 2006). In the current study we integrate social identity theory and the Psychological Continuum Model (PCM; Funk \& James, 2001, 2006) to explore how team identification develops in relation to a new sport team. The 'new team' context provides a compelling opportunity to explore how the development of identification occurs in the early stages of team development. Given the research was undertaken at the

Lock is with Griffith University, Nathan Campus, Brisbane, Queensland, Australia. Taylor and Darcy are with the University of Technology, Sydney, Sydney, New South Wales, Australia. Funk is with Temple University, Philadelphia, PA. beginning of this process the majority of consumers were in the early stages of identity development, which provided the opportunity to explore: 1) which processes lead to developed team identification? And 2) what are the manifestations of developed team identification?

\section{Literature Review and Theoretical Framework}

Social identity theory has been broadly applied to a plethora of academic contexts. From its social-psychological roots (Tajfel, 1982; Tajfel \& Turner, 1979) social identity theory has framed studies of: self-categorization (Turner, 1982); leadership in management (Hogg \& Terry, 2000); consumer-company identification in marketing (Bhattacharya \& Sen, 2003); and team identification in sport (Heere \& James, 2007; Wann \& Branscombe, 1993). Social identity theory was founded on the notion that individuals strive to join social categories which reflect positively on their self-concept (Tajfel, 1982; Tajfel \& Turner, 1979). From this basis Tajfel and Turner (1979) defined three central tenets of social identity theory. First, to maintain a positive social identity individuals will seek to join groups viewed as being equal to or slightly better than their own self-concept (Cialdini et al., 1976; Tajfel \& Turner, 1979). Second, positive social identity is based on favorable comparisons between an in-group and a relevant out-group. Therefore, individuals will maintain a positive social identity if they evaluate that the in-group is positively distinct from rivals and that they are a worthy member of the group in comparison with peers (Tajfel $\&$ Turner, 1979). Thirdly, in situations where individuals evaluate their social identity as reflecting negatively on their self-concept; they will seek to leave or positively alter the group (Tajfel \& Turner, 1979). 
Sport based research has defined the 'inception' of social identification as the point an individual develops cognition that they support a team (Wann, Melnick, Russell, \& Pease, 2001). However, key social psychological literature defines social identification as a more complex construct comprising three dimensions (Bergami \& Bagozzi, 2000; Tajfel, 1982). The first is a cognitive awareness of group membership adopted as defining identification by Wann et al. (2001). The second involves the evaluation of ingroup membership in relation to rival outgroups and other members of the ingroup (Tajfel, 1982). The third component considers the affective significance derived from cognition and evaluation. In acknowledgment of Tajfel's (1982) work we consider cognition, evaluation and affect as important facets of team identification in this study.

\section{Social Identity and Sport Consumers}

Social identity theory is an influential framework for research exploring sport fans (Fink, Trail, \& Anderson, 2002; Wann \& Branscombe, 1993). Initial studies exploring team identification measured the strength and behaviors associated with the construct (Fink et al., 2002; Wann \& Branscombe, 1993). More recent research has applied theoretical developments from social psychology to develop understanding of the construct's potential multidimensionality (Dimmock, Grove, \& Eklund, 2005; Heere \& James, 2007). Conceptually, attempts to quantify team identification — uni and multidimensionally—stem from the common hypothesis that it operates as an attitudinal barometer, predicting consumer behavior (Wann \& Branscombe, 1993).

The existing knowledge of team identification derives from primarily cross-sectional and quantitative studies of students and there is an opportunity to explore how it develops in other populations of sport consumers. Funk and James (2004) posited this agenda in their Fan Attitude Network model arguing that as identification internalizes it influences progression toward resistant and persistent team-based attitudes. This perspective is consistent with theoretical and empirical work that outlines how processes may lead to the formation and development of attitudes in relation to sport teams within the PCM framework (Funk \& James, 2001; 2006). Hence, we develop a rationale for the integration of social identity theory and the PCM to explore the development of team identification.

\section{Building a Developmental Approach to Team Identification}

There are distinct synergies between social identity theory and the PCM. For example, progression to higher stages in the PCM is accompanied by strengthened cognition of support, interaction with the self-concept, affective significance and attitude persistence (Funk \& James, 2001, 2006), which are all fundamentally linked with the central propositions of social identity theory. Furthermore, there are mutually beneficial theoretical outcomes through the combination of social identity theory and the PCM when exploring the development of identification. Social identity theory provides a basis to explore how cognitive and evaluative processes interrelate and mediate group membership, while the PCM contributes understanding of how attitude forms and progresses. Therefore, as both contribute complementary, yet unique information, considerable value is provided by integrating them to examine the process of attitude formation and team identity development in this study.

The PCM has provided a conceptual and theoretical lens guiding investigations on: attitude formation for one Australian Football League fan (de Groot \& Robinson, 2008); support of nonlocal teams (Hyatt \& Andrijiw, 2008); fan nations (Foster \& Hyatt, 2008); attitudinal change after charitable sport event participation (Phyllo, Funk, \& O'Brien, 2008); the influence of web-based interaction on attachment levels with charitable sport events (Phyllo, Funk, \& Hornby, 2009); and stage-based attitudinal and behavioral outcomes in recreational golf (Funk, Beaton, Pritchard, 2011). In the current inquiry, we focus on the processes which contribute to progression up the vertical continuum in the PCM and the outcomes associated with the awareness, attraction, attachment and allegiance stages of the model.

Logically, consumer processes in relation to sport offerings begin when an individual develops cognition that a team exists (Funk \& James, 2001, 2006). Awareness is activated by socialization processes including friends, family, advertisements, news and media (Funk \& James, 2001; Kenyon, 1969). The realization that a team exists interacts with hedonic motives (e.g., vicarious achievement, escape) dispositional needs (e.g., psychological traits and states) and social situational factors (e.g., desire to belong) to activate attraction (Funk \& James, 2006).

Attraction occurs when an individual deems a team relevant and desirable enough to select it in favor of the existing alternatives in the market (Hyatt \& Andrijiw, 2008). Thus, individuals will be attracted to support a team to benefit their social identity (Tajfel, 1982; Tajfel \& Turner, 1979) and because there is a perceived congruence between individual and group values (Elsbach \& Bhattacharya, 2001). Processes driving progression from awareness to attraction include socialization agents and lead to the satisfaction of dispositional and hedonic individual needs (Funk \& James, 2006). de Groot and Robinson (2008) found that socialization processes continued into the attraction stage, but were quickly replaced by self-esteem benefits such as the desire to associate with a successful team (Cialdini et al., 1976). At the attraction stage identification is not internalized, but attitude has formed (Funk \& James, 2006); however individuals in the attraction stage are likely to cease membership if they view a different social category as positively distinct or more likely to enhance their selfimage (Tajfel \& Turner, 1979).

Movement from attraction to attachment is activated by the realization of hedonic and dispositional needs 
and accompanied by the outcome that identification is internalized and less reliant on external forces, such as socialization processes (Funk \& James, 2006). Critically, attitudes at the attachment stage have been influenced and developed by team-based knowledge obtained through direct experiences-such as game attendance. At the attachment level identification becomes more complex and individuals connect to multiple points of the offering including: players, team, level of sport, community, coach and sport (Kwon, Trail, \& Anderson, 2005; Robinson \& Trail, 2005).

As identification has internalized in attachment, individuals' are less likely to switch to a different social category even if it is perceived to be positively distinct. Instead, individuals at the attachment stage will take action to alter the group they identify with to improve public and private evaluations (Luhtanen \& Crocker, 1992). This requires more innovative image management tactics, such as: derogating or blasting members of rival out-groups (Cialdini \& Richardson, 1980); talking positively about the in-group (Jones, 2000); and physical action to support the in-group (Fisher \& Wakefield, 1998). Attachment outcomes include: strengthening cognitive connection; affective significance; identity construction (Funk \& James, 2006); and interaction between a person's core values, self-concept and the team (Bhattacharya \& Elsbach, 2002).

The zenith of the PCM model is allegiance, whereby consumers have reached a stage of attitude persistence and are highly involved. This group of fans is engaged in support as a form of 'serious leisure', which they devote significant time, thought, effort, money and emotion toward (Gibson, Willming, \& Holdnak, 2002). Due to the seriousness and centrality of identification in allegiance, processes and outcomes form a feedback loop with the attachment stage as values, self-concept and meaning processes are constantly interacting with the development of identification and attitude (Funk \& James, 2006). Outcomes attributable to allegiant consumers include a durable and important identity, which is likely to be manifested through: membership of supporters clubs (Crawford, 2003; Funk \& James, 2001); knowledge of team history, statistics and players (Funk \& Pastore, 2000; Wann \& Branscombe, 1995); and negative perceptions of rival teams to clearly define the in-group from relevant out-groups (Dimmock et al., 2005; Wann \& Dolan, 1994). Individuals at this level derive social identity benefits from overtly displaying that they are a loyal and committed fan to others (Wann \& Branscombe, 1993), which tallies with an increased certainty in their evaluation of support (Funk \& Pastore, 2000)

The processes and outcomes defined in the PCM provide a framework to map how team identification develops. However, the trajectory of identity development in terms of the rate and level achieved through the PCM stages remains under researched. For example, one individual may progress slowly upward to the attachment stage but never progress to allegiance. In contrast, another individual may quickly move upward through the lower stages and become allegiant in a very short period of time. Hence, new evidence on how identity develops would be beneficial. Following from this statement, we review extant literature exploring new sport teams to position this review.

\section{New Sport Teams}

Literature exploring new sport teams has focused on the actual bond formed. James et al. (2002) investigated the psychological connection of season-ticket holders with a new Major League Baseball franchise in the U.S. before the team's first season. They found that season-ticket holders developed a strong cognitive bond even before a game had been played. James et al. (2002) also found that highly connected fans of the new sport team were likely to attach to multiple motives to attend, while weakly connected individuals only agreed with one purchase decision (James et al., 2002).

Building on the work of James et al. (2002) researchers have explored team identification in a new team context, finding that despite a short history, fans developed strong cognitive, affective and behavioral aspects of identification (Lock, Darcy, \& Taylor, 2009). Additional literature has explored the specific point at which identification forms in relation to a new team, highlighting the role of external social identities in this process (Lock, Taylor, \& Darcy, 2011). However, the development of identification with a new or established sport team is unexplored; therefore, this research aims to look at the processes leading to the development and internalization of identification and consequently how this relationship is manifested behaviorally. These aspects are examined through two primary research questions:

1. Which processes lead to developments in team identification?

2. What are the manifestations of developed team identification?

\section{Method}

The research design included a qualitative interview process, which reflected an inductive, interpretive and exploratory approach to data collection (Bryman, 2004). The interview process was implemented to provide a deep understanding of participants thoughts and feelings (Bryman, 2004; Jones, 1997), while exploring key processes and outcomes, which accompanied or drove a progressed sense of team identification. The methodology implemented sought to allow participants to reflect on their experiences with Sydney FC over one season and to guide the thematic development, without employing structured quantitative testing, which was beyond the scope of this study. Participant reflections were gathered through the implementation of a retrospective interview process, which sought to explore how identity changed during one season and how this influenced participant behavior. 


\section{New Sport Team Context}

In-depth interviews were conducted with foundation members of Sydney Football Club (FC), a new team competing in a brand new Australian soccer competition, the A-League. The club was a new entity, formed in 2004 as the sole A-League license holder for the city of Sydney, NSW. The newly created A-League launched its inaugural season in 2005, replacing the National Soccer League (NSL) after a prolonged period of financial instability, ethnically based trouble and mismanagement (Lock et al., 2009). The A-league began with eight teams spread across Australia, including six newly formed teams (Central Coast Mariners, Melbourne Victory, Newcastle Jets, New Zealand Knights, Queensland Roar, Sydney FC) and two established teams, which continued from the NSL (Adelaide United and Perth Glory). Before the first season of the A-League, Sydney FC recruited exManchester United striker Dwight Yorke as their marquee player (The A-League allowed teams to recruit one player outside of the salary cap) and former German FIFA World Cup winner, Pierre Littbarski as coach.

During season one of the A-League, Sydney FC yielded an average home-game attendance of 16,669which while insignificant in comparison with other football leagues globally (National Football League, English Premier League etc) — dwarfed the average attendance of the NSL, which never surpassed 5000 people leaguewide (Kemeny, 2003). In their first season, Sydney FC enjoyed considerable on-field success, which included coming second in the A-League (to qualify for the finals series) and winning the Grand Final. The Grand Final was the culmination of a play-off series between the top four teams following the 2005-2006 season, which is similar to the Super Bowl in stage of season importance, but not scope or global interest.

\section{Participants}

The research team purposively sampled (Silverman, 2000) foundation members of Sydney FC, before season one of the A-League. Foundation members were individuals that had paid to join the club before the start of Sydney FC's first season of the A-League. Therefore this group of members had been involved with the club for a maximum of one year at the time of interview. The membership database was contacted via e-mail to conduct a stage of survey research (which is not used in this study). At the end of the survey instrument, members were asked if they would be interested in a follow-up interview. A total of 240 respondents expressed an interest in followup interview. From this number, 40 foundation members replied to the contact e-mail and indicated that they would participate in a one-to-one in-depth interview. In total, 21 in-depth interviews were conducted with members of Sydney FC (see Table 1 for a breakdown of age and gender by participant). The interviews continued until data became consistent and no new themes were emerging from the interview process indicating that saturation had been reached (Glaser \& Strauss, 1977).

\section{Procedure}

The 21 members selected for interview were contacted by e-mail and suitable times and locations for interview were arranged. Interviews were conducted after season one of the A-League over a three week period. The interview schedule was developed to explore what drove the progression of team identification and to assess the manifestations of developed team identification. A semistructured in-depth interview approach was used to facilitate an atmosphere, which encouraged participants to guide the conversation, while allowing the research team to probe key aspects of the research questions as part of a nonrigid schedule (Denzin, 1989).

Before the interview commencing, participants were given an informed consent document, which included a brief description of the research project for ethical reasons. All participants were asked to read the description of the research and interview schedule and explain if any parts of the title, or research outline were unclear. If unclear on the terminology used (e.g., identification), the researcher explained the term as referring to individuals' support of and relationship with Sydney FC. Following the introduction participants were asked: "Has your level of support increased/decreased in the time since you started supporting Sydney FC?" This question was accompanied with probes, which explored: "what led to changes in the strength of your identification with Sydney FC (processes)" and "How did your behavior in relation to Sydney FC change as your identification increased (manifestation)"?

\section{Analysis}

Following each interview, the electronic recording was downloaded to the researchers' computer and transcribed. Interview data were analyzed using NVIVO 8 to catalog and code interview transcripts. The analysis of qualitative data were informed by Creswell (1998) and notes were taken during each interview to inform and elaborate upon the semistructured interview schedule. Initial analysis included reading every line of each transcript to highlight any obvious patterns in the data. Next, data were organized into themes representing overarching concepts and subthemes, which provided more specific explanations of the primary theme groups. Themes were defined during data-coding as words, phrases and paragraphs that represented a common participant response (Miles \& Huberman, 1994).

\section{Results}

Initial analysis of the interview data highlighted that, 20 of 21 interview participants perceived that their team identification was stronger, more affectively significant and internalized than it had been at the beginning of Sydney FC's first season. Interview participants outlined four subthemes explaining developed team identification, which occurred within two broader theme groups. First, 
Table 1 Development of Team Identification: Theme Saturation

\begin{tabular}{|c|c|c|c|c|c|c|}
\hline \multirow[b]{2}{*}{ Theme } & \multirow[b]{2}{*}{ Age } & \multirow[b]{2}{*}{ Gender } & \multicolumn{2}{|c|}{ Internal } & \multicolumn{2}{|c|}{ External } \\
\hline & & & Centrality & Personas & Searching & Spruiking \\
\hline Member1 & $56-60$ & Female & & $\sqrt{*}$ & $\sqrt{*}$ & \\
\hline Member2 & $60+$ & Male & $\sqrt{*}$ & & $\sqrt{*}$ & \\
\hline Member3 & $41-45$ & Female & $\sqrt{ }$ & & & \\
\hline Member4 & $41-45$ & Male & & $\sqrt{*}$ & $\sqrt{*}$ & \\
\hline Member5 & $41-45$ & Male & $\sqrt{ } *$ & & $\sqrt{ } *$ & \\
\hline Member6 & $36-40$ & Male & $\sqrt{*}$ & & $\sqrt{ } *$ & \\
\hline Member7 & $31-35$ & Male & & $\sqrt{ }$ & & \\
\hline Member8 & $41-45$ & Male & & $\sqrt{ }$ & & \\
\hline Member9 & $51-55$ & Male & $\sqrt{ } *$ & & $\sqrt{ } *$ & \\
\hline Member10 & $41-45$ & Male & $\sqrt{*}$ & $\sqrt{*}$ & $\sqrt{*}$ & \\
\hline Member11 & $56-60$ & Male & & & & \\
\hline Member12 & $26-30$ & Male & $\sqrt{*}$ & & $\sqrt{*}$ & $\sqrt{*}$ \\
\hline Member3 & $41-45$ & Male & & & $\sqrt{ }$ & \\
\hline Member1 & $31-35$ & Male & $\sqrt{*}$ & & $\sqrt{*}$ & \\
\hline Member15 & $51-55$ & Female & & $\sqrt{*}$ & $\sqrt{*}$ & \\
\hline Member16 & $1-35$ & Male & & & $\sqrt{*}$ & $\sqrt{*}$ \\
\hline Member17 & $41-45$ & Male & $\sqrt{*}$ & & $\sqrt{*}$ & $\sqrt{*}$ \\
\hline Member8 & $21-25$ & Male & $\sqrt{*}$ & $\sqrt{*}$ & & $\sqrt{*}$ \\
\hline Member19 & $26-30$ & Male & $\sqrt{*}$ & & & $\sqrt{*}$ \\
\hline Member20 & $51-55$ & Male & $\sqrt{ }$ & & & \\
\hline Member 21 & $21-25$ & Female & $\sqrt{*}$ & & & $\sqrt{*}$ \\
\hline Total N21 & & & 13 & 7 & 13 & 6 \\
\hline
\end{tabular}

*Indicates respondents selecting more than one theme

members described how the internal meaning of their team identification became a more central facet of their life. Second, the internalization of identity was manifested through members engaging in external actions to engage with and support their team. Each subtheme is presented below with a brief description:

\section{Internal Meaning}

- Centrality: Identification became a central part of respondents self-concept

- Personas: Increased affiliation with team players and coaching staff

\section{External Action}

- Searching: An increased desire to search for clubrelated news and media.

- Spruiking: Desire to promote Sydney FC to others.

Theme and subtheme responses are presented for each interview participant with their age and gender in Table 1:
Table 1 shows the coding by respondent across the two theme and four subtheme groups. Of the 20 interview participants that explained a development in their team identity, 15 members articulated two or more ways in which identification had developed.

\section{Development of Team Identification}

The initial narratives presented here provide an introduction to the more specific thematic analysis that follows. These quotations underpin the notion that identification did develop, as Member 5 explained:

I mean, I've got one season of memories, I guess, already to think about, as it goes on it becomes more and more entrenched. I always say it's one of the few constant things in your life, the team you support. Girlfriends come and go, jobs change and you've got your family, and for me club support is something that you have forever. It never changes, never goes away, but every year goes by there's another layer (Member 5). 
Member 5 considered his team identification as a relationship, likening his identification with Sydney FC to a bond with family. In addition, the passage above shows how important his team identification had become after only one season, with Member 5 stating, "It never changes".

Member 4 was more specific about the increase in his team identification, noting how it became more affectively significant: "At the start of the season I was probably a five out of ten. Towards the end of the season, yeah up towards an eight out of ten in terms of how I'd emotionally invested." To develop on the general notion of identity development, theme one explored how Sydney FC assumed a more central position in members self-concept.

\section{Theme 1-Internal 1: Centrality}

In total, 13 interview participants described how the level of internal meaning associated with their team identification grew as the bond internalized and became more affectively significant. Interview participants described how their journey and direct experience of Sydney FC during the first season led to the internalization of their team identification: "Yes, I think I did [identity developed], and it's because we saw, I think, to kind of analyze why that would be. It's because you've travelled with them along a path and you feel part of it is the simple answer to that" (Member 14). 'Traveling along a path' provided direct team experience, which Member 14 noticed manifesting in his own attitude toward Sydney FC, he continued:

I think it did increase because the fans around [sic.] got a real passion, real ownership of the team and you can see that in some of the games, where people have got really right behind it and you're getting good travelling support as well, I've become even more passionate now [towards the end of the season] (Member 14).

Member 14 described how he felt that the support group gained more ownership of the team. This ownership was associated with an increased level of 'passion' and affective significance as the first season progressed, which alluded to the development of interaction between his cognitive awareness of membership and his self-concept.

Centrality referred to identification becoming part of everyday life, as Member 6 explained: "Because it's basically on every second weekend, you are planning your things around it [Sydney FC games] and so you know you've got to change what you do." As identity assumed an increasingly central position in members' self-concept, the intensity of the relationship developed. Member 21 described how her identification shifted from an externally driven attraction through to an internalized attachment or allegiance.

At the beginning of the season it was Dad saying we're going tomorrow, the game's on. I'd forgotten, right change plans and let's go - and by the end [of the first season] I knew when the next game was three weeks in advance and I had rung friends and I had tried to get them to come.

Socialization agents drove Member 21's attendance at the start of season one. However, as her team identity internalized and her emotional investment developed Sydney FC became a more central part of her life. This comment underpinned how the development of team identification led Member 21 from a substitutable bond, which relied on her father through to an affectively significant and internalized team identification, which impacted her behavior. Member 18 explained how the development of his team identification permeated all aspects of his daily life:

Because you're thinking about it [Sydney FC] every week and as it comes along you're thinking about it. When you're at work, when you're at home, when I'm coaching the junior soccer team that I coach, I'm thinking about what happened last weekend, what's happening next weekend and you're starting to build and identify with the team (Member 18).

This passage outlined the increased complexity of identification as Member 18 spent his weeks evaluating and reflecting on his categorization. Instead of a mere knowledge of group membership, this passage alluded to the evaluative processes that operated as identification internalized and indicated a well formed and persistent attitude toward Sydney FC, which had evolved during Sydney FC's first season.

\section{Theme 2-Internal 2: Personas}

The second internal manifestation of developing team identification concerned members accruing a cognitive perception of Sydney FC's players and coaching staff. At the start of season one, Sydney FC began as a faceless entity (i.e., fans did not know who the players were), with the exception of Dwight Yorke. Member 18 described this lack of knowledge about playing staff: "When you start the season from the very beginning, you're not sure of whom the players are, you're not sure of what's going to happen." Due to this initial absence of knowledge about players in the new team context, developing cognitive awareness of player characteristics, style and contribution was an important process in the development of identification. Member 8 outlined how an initial lack of knowledge of team players changed during season-one:

I mean, even though with certain players they start developing personalities, at first they're just this amorphous bunch of people plus Dwight Yorke, you know, you've got no idea who they are... But then they all sort of develop, you get to know them, you get your sort of favourite players, there's a lot of ones you don't think are very good, you can sort of you get more involved with the actual team (Member 8). 
Members described how 'getting to know' the team was a formative process in the development of their identity. The development of internal meaning for Member 8 was influenced by direct experiences at games and observation of player performances, which led to a cognitive connection with player personas. The initially faceless nature of Sydney FC's team was an important factor in the development of identification. Members already possessed a cognitive awareness of Sydney FC's marquee signing, Dwight Yorke, which did not change; however, other players began without this persona and the development of this cognition was an important facet of identity development. The type of player was also important:

Yes. Because now what was a definite link with the players and there were certain players we never knew a lot about at the beginning of the season and I know I identify them as being key to the team, players like [Alvin] Ceccoli, who I think is a fantastic playerunderrated, definitely underrated (Member 10).

Member 10 highlighted one player as key in the development of their identification as he was seen as 'key to the team'. Other members noted how they attached to the coach: "I became a fan of Littbarski, I really like the way he handles things" (Member 15). This quote highlighted the importance of observing how the coach handled match-day situations, which was then evaluated positively by Member 15 . Next, we explore how the development of identification led to external action.

\section{Theme 3-External 1: Searching}

Interview participants reflected that searching for news on Sydney FC became an increasingly important manifestation of their team identification as season one continued. While searching for media acted as a socializing agent for some members: "I'd probably check the Sydney FC site a couple of times a day to see if anything has changed" (Member 14). For other members the thirst for team-related information occurred later in the season as an outcome of an internalized and affectively significant team identity. Searching for news on Sydney FC was a persistent course of external action resulting from developed team identification for some members:

Every day I go on the Internet, every day I go on the Internet and go into their site into their website to read what's going on, to read news. So before I never, at the start of the season I never used to do it, probably 3 games in or whatever, ever since, every day you know every time on the Internet I check without fail on the site, just to see what's happening (Member 12).

Member 12 was conscious of how searching for news and information became a more central behavioral manifestation of his team identification, which occurred during season one. Searching for news on Sydney FC provided a tool for members to legitimize their team identification.
For example, Member 6 searched for club-related media and news to learn:

Yeah [my identification increased] looking for more information about it, I suppose being a fan, wanting to be on top of it when talking to someone else about it and they might have read something about it in the paper and you haven't read it and you sort of think I have to get up to date on that. I'm a fan so I should know (Member 6).

Being up to date on club news and history allowed members to display their knowledge of team affairs; which was an important facet of group membership when Member 6 evaluated his identity in relation to other members/supporters. This comment highlighted that highly identified fans will seek to evaluate themselves in relation to other members of the same in-group as well as the in-group in relation to relevant rivals.

Additional responses indicated that Sydney FC's success in their inaugural season drove the need to search for news: "When we were in the finals, when the grand final was on it was a huge thing, it was everywhere, so whenever it's in the newspaper I will read up on FC or I try to know what's happening whenever I can" (Member 12). The success of Sydney FC led to Member 12 evaluating his team identification positively, which was manifested in his increased desire to search for news. Member 13 added:

Yeah [my identification developed], I think so. You know, as the end of the season was coming up, you're just thinking about it more, your focus is on it because it's a culmination of the end of the season so you tend to be hungrier for that sort of information. Having a look at things like websites to get that information and find out the latest gossip and things of that nature (Member 13).

The developing need of members to search for news and media articles highlighted a key behavior influenced by two evaluative processes. First, members sought to stay up to date on news and media articles on Sydney FC to demonstrate that they were a 'fan' to other in-group members. Second, the success experienced during Sydney FC's first season, led to members evaluating their categorization positively, which in turn led to the internalization and development of team identification.

\section{Theme 4-External 2: Spruiking}

The second theme describing external action was a desire to spruik and promote Sydney FC to others. For Member 21, this process resulted from her own enjoyment of supporting Sydney FC: "The fact that I enjoyed it so much is something that I wanted to share with friends that had less taste than me [laughs]." Member 21 explained how her evaluations of the personal enjoyment and value she derived from support led to the external action of promoting Sydney FC to her friends that did not support the club. 
Member 12 spruiked Sydney FC to leverage a state of attraction for people that did not support Sydney FC by acting as a socialization agent himself:

I talk to them [friends] about Australia [Socceroos] about Sydney FC, about how good the A-League is, how everybody needs to watch games to support it [the A-League]. I kind of feel it's my duty to try and sell the game to everybody I know, to all my friends and I think I do that well [laughs].

The above quote highlights the outcome of Member 12's own evaluations of his team identification. He sought to actively promote Sydney FC to others as a means to positively alter the social category he identified with. Another interview participant noticed this theme emerging as his team identification developed: "I just kept raving on about it [Sydney FC], you know, I see them and I still play in the over-35s so every game I go to and training I just talk about it. Every time there was [sic] special offers for tickets I used to get all my mates to come along" (Member 12). This overt support of Sydney FC revealed a notable outcome of developed team identification, which was based on attempts to positively alter public evaluations of the in-group.

\section{Discussion}

The findings of this study illustrate four main outcomes. First team identification did develop and as it become a more central part of members self-concept it influenced day to day behavior and planning. Second, developing understanding of players led to members' team identities becoming more complex and affectively significant. Third, searching for news and media on Sydney FC was a manifestation of developed team identification, which extended previous conceptualizations of socialization processes. Fourth, we found that members actively sought to promote Sydney FC to others as a tactic to make the group more positively distinct. These findings are displayed in Table 2, below. We include the four subthemes and a brief narrative explaining how individuals defined their identification at the start of the season and as it progressed to an internalized relationship. PCM stages are included at the top of the model; however, narratives have been placed as externalized or internalized as differentiating between attachment and allegiance based on the qualitative data collected is problematic.

\section{Centrality}

Centrality was defined through the progression from an externally driven, substitutable bond to an internalized and consuming identity. The internalization of fan-team bonds is strongly linked with attitude persistence (Funk \& James, 2004), which was manifested in this research through an increased internal meaning and need to engage with the new sport team. While we found support for previous literature explaining the role of socialization processes in the development of attraction to support (de Groot \& Robinson, 2008; Funk \& James, 2006), data here suggested that the key process leading to progression to attachment was direct team-related experience (Funk \& James, 2001; Funk \& Pastore, 2000). At the start of Sydney FC's first season socialization agents played a key role in activating attraction. However, as team identification developed and internalized it became less reliant on external forces as members developed a more 'serious' identity with the new team (Gibson et al., 2002).

The centrality theme advanced previous work by showing how intense and consuming identification could become after one season. Previously de Groot and Robinson (2008) linked the attachment stage of the PCM with social belonging and the development of affective significance. This aligned with Tajfel's (1982) assertion that while cognitive and evaluative aspects of identification were ever present, affective significance was an outcome of more significant social identities. The development of identification was linked with affective significance as has already been shown (de Groot \& Robinson, 2008; Funk \& James, 2006); however we found that participants noted shifting their priorities as their attitude with Sydney FC became a central aspect of their self-definition. Instead of being prompted to attend games by socializing forces, members were calling friends in advance to arrange attendance and engaging in activities to support Sydney FC as a central aspect of their identity processes (Fisher \& Wakefield, 1998).

Table 2 Development of Identification Themes with PCM Stages

\begin{tabular}{|c|c|c|c|}
\hline & & Awareness & Attachment \\
\hline & Theme & External & Internalized \\
\hline \multirow[t]{2}{*}{ Internal meaning } & Centrality & $\begin{array}{l}\text { Externally driven identity, which had } \\
\text { little influence on behavior }\end{array}$ & $\begin{array}{l}\text { Internalized identification, which influenced daily } \\
\text { behavior and planning }\end{array}$ \\
\hline & Personas & $\begin{array}{l}\text { Players and team seen as a faceless and } \\
\text { amorphous group of people }\end{array}$ & $\begin{array}{l}\text { Knowledge of and preference for specific player/s } \\
\text { formed through direct experience }\end{array}$ \\
\hline \multirow[t]{2}{*}{ External action } & Searching & $\begin{array}{l}\text { News as socialization process activating } \\
\text { attraction to attend }\end{array}$ & $\begin{array}{l}\text { News became a core manifestation of identity } \\
\text { based on intragroup evaluation and team success }\end{array}$ \\
\hline & Spruiking & $\begin{array}{l}\text { Little communication to others about } \\
\text { identification }\end{array}$ & $\begin{array}{l}\text { Spruiking became a key tool to promote team to } \\
\text { others and positively alter group image }\end{array}$ \\
\hline
\end{tabular}




\section{Personas}

The lack of a cognitive awareness of players, player characteristics, personalities and performances was shown to be an issue faced by new sport teams as they have not acquired any particular reputation, image, rituals, iconic symbols or brand presence (Lock et al., 2011). Direct experience (Funk \& James, 2001), gathered from attending games provided a cognitive awareness of player characteristics, traits, performances and personality, which was influential in the development of team identification. As members maintained an existing level of cognition of Dwight Yorke, he had little impact on the identity processes of the members interviewed. Instead, lesser known players who members developed cognitive awareness of during season one and were recognized as 'key team members' were most influential in the process of identity development. This finding supported other work showing that players are only significant to fans if they are perceived as being loyal and influential team members (Neale \& Funk, 2006).

The development of identification with players and the team indicated a more complex relationship, which is associated with the attachment and allegiance stages of the PCM (Funk \& James, 2006). It also aligned with other work highlighting that individuals will associate themselves with multiple facets of the offering when attachment or identification becomes affectively significant (Funk, Mahony, Nakazawa, \& Hiriwaka, 2000; Robinson \& Trail, 2005). The contribution of this theme was to elaborate the influence of cognitive awareness of players on the development of identification. The processbased change from amorphous collection of players, to a collective group of individuals that developed personas during season one of Sydney FC's existence was influential in the development of identification.

\section{Searching}

Previous research utilizing the PCM has outlined the role of news and media as a socialization agent, which can activate attraction. Here, searching for news was observed primarily as an outcome of developed team identification. Due to the extensive discussions that have explained how socialization agents activate attraction (Funk \& James, 2001, 2006) we focus on the theoretical implications of searching for news as a manifestation of identity development.

Social identity theory provides a basis to understand how individuals evaluate group memberships (Tajfel \& Turner, 1979) and the maintenance of a positive social identity based on intergroup comparison has been extensively covered (Brewer \& Weber, 1994). However, we found that intragroup evaluations (Turner, 1982) play an important role in the need to search for news. Searching for news acted as an identity maintenance behavior, which allowed members to display to other fans that they were up to date on team news and affairs
(Wann \& Branscombe, 1995). Displaying a high level of team based knowledge in relation to other fans allowed individuals to evaluate their group knowledge in relation to other group members favorably (Tajfel, 1982). This positive evaluation contributed additional understanding of image management tactics used by individuals at the attachment and allegiance stages of the PCM, which developed during season one.

Positive evaluations of team identification were also impacted by team performances, which in turn drove an increased desire to 'search' toward the end of season one. Team success has been shown to drive developments in attitude strength at the attraction and attachment stages of the PCM due to the satisfaction of hedonic needs (Funk \& James, 2006). The success experienced by Sydney FC in their first season activated an increased desire to search for team-related news and media, which supported other research noting that individuals will seek to align themselves with social categories, which reflect positively on their self-concept (Cialdini et al., 1976). Searching for news acted as a manifestation of developed team identification that diversified current applications of the role played by news and media in the attitude formation and identification of sport fans. However, the application of this finding to all new teams requires consideration as Sydney FC experienced a highly successful initiation to the A-League, which conceivably influenced this finding.

\section{Spruiking}

Spruiking described attempts by Sydney FC members to positively alter perceptions of the team, which extended current understanding of the outcomes associated with fans at the attachment and allegiance levels, within the PCM (Funk \& James, 2001; 2006). This finding had tangential links with the Market Maven concept (Feick \& Price, 1987). However, instead of acting as an information hub because of market based expertise, spruiking represented a tool to positively alter members' social identity as fans of Sydney FC. This behavior also provided members with a mechanism to show others that they were loyal and committed fans (Wann \& Branscombe, 1993).

While attitude persistence, resistance, complexity and impact have been attributed to the allegiance stage of the PCM, here members described that they acted at an organic marketing level through cajoling friends and colleagues to support the team and attend games to achieve a positively distinct group image (Tajfel \& Turner, 1979). Furthermore, this external action contributed understanding that as identity developed, members spent time actively seeking to improve public evaluations of 'their team'. Conceptually, this external action showed how attached/allegiant fans can become socialization agents acting in the induction of new consumers to the awareness and attraction stages of the PCM. 


\section{Conclusion and Recommendations}

This study has contributed to existing literature by demonstrating that understanding of team identification can be expanded by viewing the construct as a developmental process. Through the integration of social identity theory and the PCM, we have extended previous work exploring how developments in team identification are driven and manifested for individuals. This study provided empirical support to the viability of the PCM as a framework to test existing theories and models of sport fan behavior and the synergies between social identity theory and PCM frameworks provided a profitable theoretical unison, which can contribute to future work exploring the development of team identification.

This study has contributed to theory in four ways. First, the development of identification transitioned individuals from an externally driven relationship to an internalized state where their group membership influenced cognition, behavior and day to day planning. This progression in team identification was driven by direct team-based experiences. Second, internal meaning was derived from the transition of the playing group from an 'amorphous' group of players to a set of individually distinct players with developed public personas. Developing understanding of the perceived level of value specific players had to the team was a key factor in the development of player personas garnered from direct experience at games. Third, this research has demonstrated that searching for news and media articles is a team directed outcome of developed identification in the upper stages of the PCM, in addition to acting as a socialization agent activating preference at the base-levels of the model. The key process driving the need to search for news derived from individuals seeking to evaluate their identity as a supporter of Sydney FC in comparison with other supporters positively. Fourthly, developed identification was manifested through members actively seeking to benefit Sydney FC by spruiking and promoting the club to others. This action was driven by members desire to positively evaluate their identification as a Sydney FC fan publicly.

Stemming from the contributions to theory, three practical recommendations are presented. First, because direct experience acted as a key process leading to identification becoming a more central aspect of members' self-concept new teams should be acutely aware of avenues to facilitate opportunities for individuals to see live matches and interact with the team in the early stages of team development. Examples include ticketing initiatives and opportunities for consumers' to meet players and coaching staff through outreach functions.

Second, following the role media articles were shown to play as identity developed, sport teams should be cognizant of the role news and media articles can play in attitude formation. Specifically, clubs should seek to provide news for fans, which seeks to subtly disseminate educational and enlightening news and media articles and materials for consumers to learn about player personas, team statistics and constantly seek to develop a feeling of history, which new sport teams' lack.

Finally, sport teams should develop strategies to encourage their members to spruik the benefits of involvement as a way to develop the membership and, hence, fan base. This form of (organic or whisper marketing) could be encouraged through a series of marketing initiatives to encourage individuals to attract new members via the spruiking manifestation. Such initiatives would seek to encourage spruiking, which has highly positive outcome for sporting teams.

\section{Future Research and Limitations}

Two distinct agendas for future research arise from this study. First, future scholarship would benefit from greater use of longitudinal qualitative research designs to gather in-depth data at different points of a new team's first and subsequent seasons. This agenda would be usefully encapsulated in a mixed-method design which places individuals within the PCM stages utilizing quantitative methods as a precursor to target individuals that have moved up or down PCM stage during one or more seasons. Second, quantitatively focused research utilizing multidimensional and uni-dimensional measures of team identification should be conducted to explore how the cognitive, affective and evaluative dimensions of social identity change over time for individuals segmented within the PCM stages.

As with all research studies, this research has limitations and we acknowledge three main limitations. First, the utilization of a qualitative methodology allowed us to gain in-depth reflections from foundation members of a new team regarding the development of their team identification but the data were only for one team and a small number of its supporters. Future research could profitably explore alternate contexts and cases to investigate the broader transferability of the findings. Second, the retrospective interview process meant that respondents were only interviewed at one point in time. Therefore, respondent perspectives depended on recall and reflection and did not gather thoughts and feelings at different points in the season. While we argue the suitability of this method for this initial inquiry, future work could to apply longitudinal or time-series methods to explore identity development. Third, the findings presented in this paper were based on a team which was hugely successful in its first season, winning the league competition. The process of team identity development may conceivably be different in other less successful contexts.

\section{References}

Bergami, M., \& Bagozzi, R. (2000). Self categorization, affective commitment and group self esteem as distinct aspects of social identity in the organization. The British Journal of Social Psychology, 39(4), 555-577.

Bhattacharya, C., \& Elsbach, K. (2002). Us versus them: The roles of organizational identification and disidentification 
in social marketing initiatives. Journal of Public Policy \& Marketing, 21(1), 26-36.

Bhattacharya, C., \& Sen, S. (2003). Consumer-company identification: A framework for understanding consumers' relationships with companies. Journal of Marketing, 67(2), 76-88.

Brewer, M., \& Weber, J. (1994). Self-evaluation effects of interpersonal versus intergroup social comparison. Journal of Personality and Social Psychology, 66(2), 268-275.

Bryman, A. (2004). Social research methods (2nd ed.). New York: Oxford University Press.

Cialdini, R., Borden, R., Thorne, A., Walker, M., Freeman, S., \& Sloan, L. (1976). Basking in reflected glory: Three (football) field studies. Journal of Personality and Social Psychology, 34(3), 366-375.

Cialdini, R., \& Richardson, K. (1980). Two indirect tactics of image management: Basking and blasting. Journal of Personality and Social Psychology, 39, 406-415.

Crawford, G. (2003). The career of the sport supporter: The case of the manchester storm. Sociology, 37(2), 219-237.

Crisp, R., \& Hewstone, M. (2007). Multiple social categorization: Context, process and social consequence. In R. Crisp \& M. Hewston (Eds.), Multiple social categorization (2 ed.). New York: Psychology PRess.

de Groot, M., \& Robinson, T. (2008). Sport fan attachment and the psychological continuum model: A case study of an australian football league fan. Leisure/Loisir, 32(1), 117-138.

Denzin, N. (1989). The research act: A theoretical introduction to sociological method. New York: Prentice Hall.

Dimmock, J., Grove, J., \& Eklund, R. (2005). Reconceptualising team identification: New dimensions and their relationship to intergroup bias. Group Dynamics, 9(2), 75-86.

Elsbach, K., \& Bhattacharya, C. (2001). Defining who you are by what you're not: Organizational disidentification and the national rifle association. Organization Science, 12(4), 393-413.

Feick, L., \& Price, L. (1987). The market maven: A diffuser of marketplace information. Journal of Marketing, 51(1), 83-97.

Filo, K., Funk, D., \& Hornby, G. (2009). The role of web site content on motive and attitude change for sport events. Journal of Sport Management, 23(1), 21-40.

Filo, K., Funk, D., \& O'Brien, D. (2008). It's really not about the bike: Exploring attraction and attachment to the events of the lance armstrong foundation. Journal of Sport Management, 22, 501-525.

Fink, S., Trail, G., \& Anderson, D. (2002). An examination of team identification: Which motives are most salient to its existence? International Sports Journal, 6(2), 195-207.

Fisher, R., \& Wakefield, K. (1998). Factors leading to group identification: A field study of winners and losers. Psychology and Marketing, 15(1), 23-40.

Foster, W., \& Hyatt, C. (2008). Inventing team tradition: A conceptual model for the strategic development of fan nations. European Sport Management Quarterly, 8(3), 265-287.

Funk, D., \& James, J. (2001). The psychological continuum model: A conceptual framework for understanding an individual's psychological connection to sport. Sport Management Review, 4(2), 119-150.

Funk, D., \& James, J. (2004). The fan attitude network (fan) model: Exploring attitude formation and change among sport consumers. Sport Management Review, 7(1), 1-26.
Funk, D., \& James, J. (2006). Consumer loyalty: The meaning of attachment in the development of sport team allegiance. Journal of Sport Management, 20(2), 189-217.

Funk, D., Mahony, D., Nakazawa, M., \& Hiriwaka, S. (2000). Spectator motives: Differentiating among objects of attraction in professional football. European Journal of Sport Management, 7, 51-67.

Funk, D., \& Pastore, D. (2000). Equating attitudes to allegiance: The usefulness of selected attitudinal information in segmenting loyalty to professional sports teams. Sport Marketing Quarterly, 9(4), 175-184.

Gibson, H., Willming, C., \& Holdnak, A. (2002). We're gators. Not just gator fans": Serious leisure and university of florida football. Journal of Leisure Research, 34(4), 397-426.

Glaser, B., \& Strauss, A. (1977). Grounded theory. In N. Denzin (Ed.), Sociological methods: A sourcebook. New York: McGraw Hill.

Heere, B., \& James, J. (2007). Stepping outside the lines: Developing a multi-dimensional scale based on social identity theory. Sport Management Review, 10, 65-91.

Hogg, M., \& Terry, D. (2000). Social identity and self-categorization processes in organizational contexts. Academy of Management Review, 25(1), 121-140.

Hyatt, C., \& Andrijiw, A. (2008). How people raised and living in ontario became fans of non-local national hockey league teams. International Journal of Sport Management and Marketing, 4(4), 338-355.

James, J. (2001). The role of cognitive development and socialization in the initial development of team loyalty. Leisure Sciences, 23(4), 233-261.

James, J., Kolbe, R., \& Trail, G. (2002). Psychological connection to a new sport team: Building or maintaining the consumer base. Sport Marketing Quarterly, 11(4), 215-225.

Jones, I. (1997). Mixing qualitative and quantitative methods in sports fan research The Qualitative Report, 3(4), Online article.

Jones, I. (2000). A model of serious leisure identification: The case of football fandom. Leisure Studies, 19(4), 283-298.

Kemeny, A. (2003). Report of the NSL task-force: Into the structure of a new national league soccer competition. Sydney: Australian Soccer Association.

Kenyon, G. (1969). Sport involvement: A conceptual go and some consequences thereof. In G. Kenyon (Ed.), Sociology of sport (pp. 77-99). Chicago: The Athletic Institute.

Kwon, H., Trail, G., \& Anderson, D. (2005). Are multiple points of attachment necessary to predict cognitive, affective, conative, or behavioral loyalty? Sport Management Review, 8(3), 255-270.

Lock, D., Darcy, S., \& Taylor, T. (2009). Starting with a clean slate: An analysis of member identification with a new sports team. Sport Management Review, 12(1), 15-25.

Lock, D., Taylor, T., \& Darcy, S. (2011). In the absence of achievement: The formation of new team identification. European Sport Management Quarterly, 11(2), 171-192.

Luhtanen, R., \& Crocker, J. (1992). A collective self-esteem scale: Self-evaluation of one's social identity. Personality and Social Psychology Bulletin, 18(3), 302.

Miles, M., \& Huberman, A. (1994). Qualitative data analysis: An expanded sourcebook (2nd ed.). Thousand Oaks: Sage.

Neale, L., \& Funk, D. (2006). Investigating motivation, attitudinal loyalty and attendance behaviour with fans of australian football. International Journal of Sports Marketing \& Sponsorship, 7(4), 307-318. 
Robinson, M., \& Trail, G. (2005). Relationships among spectator gender, motives, points of attachment, and sport preference. Journal of Sport Management, 19(1), 58-80.

Silverman, D. (2000). Doing qualitative research: A practical handbook. London: Sage Publications.

Snyder, C., Lassegard, M., \& Ford, C. (1986). Distancing after group success and failure: Basking in reflected glory and cutting off reflected failure. Journal of Personality and Social Psychology, 51, 382-388.

Tajfel, H. (1972). Experiments in a vacuum. In J. Israel \& H. Tajfel (Eds.), The context of social psychology; a critical assessment (pp. 69-119). London: published in cooperation with the European Association of Experimental Psychology by Academic Press.

Tajfel, H. (1982). Social psychology of intergroup relations. Annual Review of Psychology, 33(1), 1-39.

Tajfel, H., \& Turner, J. (1979). An integrative theory of intergroup conflict. In W. Austin \& S. Worchel (Eds.), The social psychology of intergroup relations (pp. 33-47). Monterey: Brooks/Cole Publishing Company.

Turner, J. (1982). Towards a cognitive redefinition of the social group. In H. Tajfel (Ed.), Social identity and intergroup relations. Cambridge: Cambridge University Press.

Wann, D., \& Branscombe, N. (1993). Sports fans: Measuring degree of identification with their team. International Journal of Sport Psychology, 24, 1-17.

Wann, D., \& Branscombe, N. (1995). Influence of identification with a sports team on objective knowledge and subjective beliefs. International Journal of Sport Psychology, 26, 551-567.

Wann, D., \& Dolan, T. (1994). Spectators' evaluations of rival and fellow fans. The Psychological Record, 44(3), 351-358.

Wann, D., Melnick, M., Russell, G., \& Pease, D. (2001). Sport fans: The psychology and social impact of spectators. New York: Routledge. 